\title{
Mothers infected with SARS-CoV-2 reveals a mild impact on newborns
}

\author{
Pu Yang \\ Zhongnan Hospital of Wuhan University \\ Junwen Zheng \\ Zhongnan Hospital of Wuhan University \\ Pin Liu \\ Zhongnan Hospital of Wuhan University

\section{Xia Wang} \\ Zhongnan Hospital of Wuhan University \\ Dongchi Zhao (D zhao_wh2004@hotmail.com ) \\ Zhongnan Hospital of Wuhan University
}

\section{Short Report}

Keywords: Mothers; SARS-CoV-2; impact; newborns

Posted Date: August 18th, 2020

DOI: https://doi.org/10.21203/rs.3.rs-60629/v1

License: (c) (i) This work is licensed under a Creative Commons Attribution 4.0 International License. Read Full License 


\section{Abstract}

Could pregnant women infected with COVID-19 cause adverse consequences for their newborns?

2. Mothers infected with COVID-19 did not cause serious adverse reactions during term labor, but premature infants were prone to gastrointestinal complications.

3. It is necessary to strengthen the protective measures of nosocomial infection in NICU. Although the outbreak of SARS-CoV-2 has a serious impact on human health, the impact on newborns seems to be relatively moderate

\section{Introduction}

SARS-CoV-2 is highly infectious and can cause infection in all age groups, leading to COVID-19[1, 2], while there are still many ambiguous measures in the perinatal management $[3,4]$. The aim of this study is to summarize the impact of pregnant women infected with SARS-CoV-2 on newborns in the third trimester.

\section{Methods}

A retrospective study was conducted on 73 newborns born to 70 mothers infected with SARS-CoV-2 from January 20, 2020 to March 5, 2020 in Zhongnan Hospital of Wuhan University. SARS-CoV-2 nucleic acid was tested from newborns nasopharyngeal swab at day 0,1,5 after birth. The data of maternal pregnancy history, newborn birth history, clinical features, laboratory and imaging results, treatment measures and outcome were collected. This study was approved by the Medical Ethical Committee of Zhongnan Hospital of Wuhan University (clinical ethical approval number 2020004).

\section{Results}

There were 7 cases of natural delivery and 63 cases of cesarean section. 37 women had no symptoms before delivery, 33 women had fever, cough, runny nose, abdominal pain or diarrhea. After delivery, 2 mothers were admitted to ICU, and there was no death. Among the newborns, 35 were male and 38 were female, including 3 pairs of twins, 17 premature infants and 56 term infants. The median GA and BW were 38.4 weeks and $3 \mathrm{~kg}$ respectively. The Apgar scores of 1 minute and 5 minutes were 8.7 and 9.7, respectively (Table 1 ).

Red blood cell and hemoglobulin of all newborn were at normal range. Half of the preterm infants with gestational age less than 32 weeks had a decrease in white blood cell and neutrophil counts. Procalcitonin increased slightly in $24.7 \%$ cases, and C-reactive protein was normal. The detection of SARS-CoV-2 nucleic acid in nasopharynx swabs of all newborns was negative. 58 from 68 cases showed normal X-ray chest film, 10 cases had lung shadow or ground glass-like changes. 
There were 15 cases of vomiting and feeding intolerance, 9 cases of abdominal distention. 9 preterm newborns were treated with nasal continuous positive pressure, and 6 with intratracheal injection of pulmonary surfactant. No infant received prophylaxis or therapeutic antiviral treatment. When these infants were confirmed with free of SARS-CoV-2 infection and related complications, family isolation measures were taken. The babies began to resume breastfeeding when mother's viral nucleic acid tests were negative. Up to date, 70 cases have been cured and discharged, 3 are still hospitalized. No deaths occurred.

\section{Discussion}

The global spread of COVID-19 poses a severe challenge to the delivery of pregnant women and the management of newborns[4]. Maternal infection of SARS-CoV-2 may have the potential adverse consequences for the normal growth and development of newborns[5].

Due to the lack of early understanding of the risk of pregnant women with COVID-19, these newborns were hypothesized "at risk", and admitted to neonatal intensive care unit for observation and formula feeding. While, the results showed that there was no specific difference in clinical characteristics between the newborns born to mother with COVID-19 infection and the those of other normal childbirth.

Our data show that, although the outbreak of SARS-CoV-2 has a serious impact on human health, the impact on newborns seems to be relatively moderate. Most of these newborns were in the normal physiological state and the premature complications might be related to their gestational age and birth weight. This study has limitations. The objects of observation were newborns in the third trimester and the observation time was short. The health status of these infants will be followed up in the future.

\section{Declarations}

Author Contributions: Dr. Zhao had full access to all of the data in the study and take responsibility for the integrity of the data and the accuracy of the data analysis.

Drs Yang, Liu and Zheng are co-first authors, contributed equally to the work.

Concept and design: Drs.Yang, Liu, Zheng and Zhao.

Acquisition, analysis, or interpretation of data: Wang and Zhang.

Drafting of the manuscript: Yang, Liu, Zheng and Zhao.

Critical revision of the manuscript for important intellectual content: Wang, Liu and Zhao.

Statistical analysis: Yang, Liu, Zheng and Zhao.

Supervision: Dr. Dongchi Zhao 
Conflict of Interest Disclosures: None reported.

Funding/Support: This work was supported by the Science and Technology Department of Hubei Province (grant number: 2019-nCoV. No.2020FCA011).

Disclaimer: The opinions expressed herein reflect the collective views of the coauthors.

Acknowledgment: All authors approved the final manuscript as submitted and agree to be accountable for all aspects of the work.

The present study was registered as a clinical study in the Chinese Clinical Trial Registry(ChiCTR-ORC-16008872) and the Institutional Review Board of Zhongnan Hospital of Wuhan University approved the study(approval no. 2015019), and all guardians signed informed consents that the participates consented to participate and/or publish.

\section{References}

[1]. Wu, Z. and J.M. McGoogan, Characteristics of and Important Lessons From the Coronavirus Disease 2019 (COVID-19) Outbreak in China: Summary of a Report of 72314 Cases From the Chinese Center for Disease Control and Prevention. JAMA, 2020.

[2]. Chen, H., et al., Clinical characteristics and intrauterine vertical transmission potential of COVID19 infection in nine pregnant women: a retrospective review of medical records. The Lancet, 2020. 395(10226): p. 809-815.

[3]. Yang, P., et al., Corona Virus Disease 2019, a growing threat to children? Journal of Infection, 2020.

[4]. Rasmussen, S.A., et al., Coronavirus Disease 2019 (COVID-19) and Pregnancy: What obstetricians need to know. American Journal of Obstetrics and Gynecology, 2020.

[5]. Yang, P., et al., Clinical characteristics and risk assessment of newborns born to mothers with COVID-19. Journal of Clinical Virology, 2020: p. 104356.

\section{Tables}

Table 1. Demographics, clinical characteristics, treatment and outcomes of newborns with COVID-19 mothers 


\begin{tabular}{|c|c|c|c|c|c|}
\hline & & $\begin{array}{l}\text { Total } \\
(\mathrm{n}=73)\end{array}$ & $\begin{array}{l}\text { GA<32 weeks } \\
\text { preterm }(n=6)\end{array}$ & $\begin{array}{l}\mathrm{GA} \geq 32,<37 \text { week's } \\
(\mathrm{n}=11)\end{array}$ & $\begin{array}{l}\text { GA } \geq 37 \text { weeks } \\
(n=56)\end{array}$ \\
\hline \multicolumn{6}{|l|}{$\operatorname{Sex}(n, \%)$} \\
\hline & Male & $35(47.9 \%)$ & $3(50.0 \%)$ & $3(27.3 \%$ & $29(51.8 \%)$ \\
\hline & Female & $38(52.1 \%)$ & $3(50.0 \%)$ & $8(72.7 \%)$ & $27(48.2 \%)$ \\
\hline \multicolumn{2}{|c|}{$\mathrm{GA} \rrbracket$ weeks $\square($ median,IQR) } & $38.4\left(37^{+1}-39^{+4}\right)$ & $31.9\left(31^{+6}-32\right)$ & $36.3\left(35^{+6}-36^{+3}\right)$ & $39.07\left(38^{+2}-39^{+5}\right)$ \\
\hline \multicolumn{2}{|c|}{$\mathrm{BW} \square \mathrm{kg} \square($ median,IQR) } & $3.0(2.67-3.47)$ & $1.5(1.49-1.57)$ & $2.6(2.3-2.7)$ & $3.21(2.9-3.5)$ \\
\hline PROM (n, \%) & & $16(21.9 \%)$ & $2(33.3 \%)$ & $5(45.5 \%)$ & $9(16.1 \%)$ \\
\hline \multicolumn{6}{|c|}{ Apgar scores (mean \pm SD) } \\
\hline & $1 \min$ & $8.7 \pm 0.7$ & $7.3 \pm 1.2$ & $8.2 \pm 0.6$ & $9.0 \pm 0.2$ \\
\hline \multirow[t]{2}{*}{$(n, \%)$} & $\leq 7$ & $3(4.1 \%)$ & $2(33.3 \%)$ & $1(9.1 \%)$ & 0 \\
\hline & $5 \mathrm{~min}$ & $9.7 \pm 0.6$ & $8.5 \pm 1.2$ & $9.2 \pm 0.6$ & $10.0 \pm 0.2$ \\
\hline$(n, \%)$ & $\leq 7$ & $1(1.4 \%)$ & $1(16.7 \%)$ & 0 & 0 \\
\hline \multicolumn{6}{|c|}{ Clinical symptoms $(\mathrm{n}, \%)$} \\
\hline \multirow[t]{2}{*}{ On admission } & Groan & $6(8.2 \%)$ & $2(33.3 \%)$ & $3(27.3 \%)$ & $1(1.8 \%)$ \\
\hline & Tachypnea & $4(5.5 \%)$ & $4(66.7 \%)$ & 0 & 0 \\
\hline \multirow[t]{6}{*}{ Complications } & Vomit & $15(20.6 \%)$ & 0 & 0 & $15(28.3 \%)$ \\
\hline & Abdominal distension & $9(12.3 \%)$ & 0 & $2(18.2 \%)$ & $7(12.5 \%)$ \\
\hline & Hematochezia & $2(2.7 \%)$ & 0 & $1(9.1 \%)$ & $1(1.8 \%)$ \\
\hline & Rash & $2(2.7 \%)$ & 0 & 0 & $2(3.6 \%)$ \\
\hline & NEC & $1(1.4 \%)$ & 0 & $1(9.09 \%)$ & 0 \\
\hline & $\mathrm{BPD}$ & $3(4.1 \%)$ & $3(50.0 \%)$ & 0 & 0 \\
\hline Outcomes $(n, \%)$ & Discharged & $70(95.9 \%)$ & $3050.0 \%) \square$ & $11(100.0 \%)$ & $56(9100.0 \%)$ \\
\hline \multicolumn{2}{|c|}{ LOS $\square$ days $\square($ median,IQR) } & $8(7-15)$ & $1^{*}$ & $9(6.5-17)$ & $8(7-10.8)$ \\
\hline \multicolumn{6}{|l|}{ Treatments $(\mathrm{n}, \%)$} \\
\hline \multirow{4}{*}{ … } & Antibiotic & $40(54.8 \%)$ & $6(100 \%)$ & $8(72.7 \%)$ & $26(46.4 \%)$ \\
\hline & Antiviral treatment & 0 & 0 & 0 & 0 \\
\hline & $\mathrm{nCPAP}$ & $9(12.3 \%)$ & $6(100 \%)$ & $3(27.3 \%)$ & 0 \\
\hline & Pulmonary Surfactant & $6(8.2 \%)$ & $6(100 \%)$ & 0 & 0 \\
\hline \multicolumn{2}{|c|}{ Chest X-ray $(\mathrm{n} \%)$} & $N=68$ & $N=6$ & $N=11$ & $N=51$ \\
\hline & Normal & $57(83.8 \%)$ & $4(66.7 \%)$ & $9(81.8 \%)$ & $45(86.3)$ \\
\hline & Patch shadows & $3(4.41 \%)$ & 0 & 0 & $3(5.9 \%)$ \\
\hline & Decreased lung transmittance & $7(10.3 \%)$ & $2(33.3 \%)$ & $2(18.2 \%)$ & $3(5.9 \%)$ \\
\hline
\end{tabular}

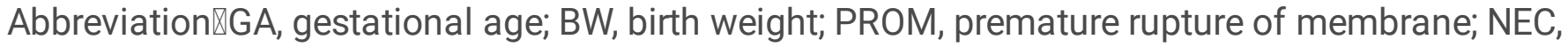 neonatal; BPD, bronchopulmonary dysplasia; LOS,length of stay; *, preterm infants of GA $<32 \mathrm{~W}$ have been still hospitalized.}

